\title{
PROGNOSTIC FACTORS OF MORBIDITY IN ENTERIC PERFORATION IN A PERIPHERAL HOSPITAL
}

\author{
Kanwar Singh Goel ${ }^{1}$, Nikhil Goel ${ }^{2}$
}

${ }^{1}$ Senior Surgeon, Department of General Surgery, Maharaja Agrasen Hospital, Jind, Haryana.

${ }^{2}$ Ex. Senior Resident, BPS Government Medical College for Women, Khanpur Kalan, Sonepat, Haryana.

\section{ABSTRACT}

\section{BACKGROUND}

In cases of intestinal perforation because of typhoid, the type of patients that are to be admitted needs to be sorted out in a peripheral centre like ours so as to avoid unnecessary mortality and bad effects thereafter.

Aim is to study the filtering criteria to be used at the time of initial admission of cases of enteric perforation following typhoid fever, treated at a peripheral centre for various prognostic factors of morbidity, like sex, delay in reporting the organised hospital care, delay in definitive surgery, peritoneal fluid laden with pus and faeculent material to the tune of more than a litre and presence of multiple perforations so that a case needing the intensive monitoring and therapy of a tertiary care center is not admitted.

\section{MATERIALS AND METHODS}

A total of 106 cases were studied where after applying screening/filter of cardiac status, chest status, various clinical factors, haematological and biochemical factors, 88 cases were segregated for further management at our centre which is not as equipped as a tertiary care centre but has all necessary gadgets to deal with routine emergency. These 88 cases were proved to be of typhoid by Widal test and/or blood culture and/or histopathology of the excised margins of the ulcer during exploratory laparotomy. After optimisation, these patients were taken up for exploratory laparotomy by midline incision. Operative findings consisting of volume and quality of peritoneal fluid (Intestinal, faeculent or pus or mixed) as well as site and number of intestinal perforations were recorded. All the peritoneal fluid was drained, perforation was repaired or resection carried out in two layers followed by thorough peritoneal lavage. A wide bore drain was placed in the pelvis and laparotomy wound was closed. Patient was closely monitored in postoperative period for vitals, urine output and general progress. Patient was allowed p.o. after positive bowel sounds or passing flatus. Any complication like superficial wound dehiscence or burst abdomen or stitch sepsis was accordingly managed. Stitches were removed on 12-14th post-operative day.

\section{RESULTS}

In the present series, there were total of 88 patients. 60 were males and 28 were females. The mean age of the patients was 38.34 $( \pm 12.08$ ). Operation was done within 12 hours of onset of symptoms in 48 patients while 40 cases underwent surgery 12 hours of onset of symptoms. Morbidity was $9 / 48(18.75 \%)$ in former group and 20/40 (50\%) in later group. Detailed analysis revealed that delay was mostly before reaching the hospital. It was also found that 62 patients out of 88 had received some kind of treatme nt before reaching our hospital in form of intravenous fluids, antibiotics and analgesics. Remaining 26 patients reached the hospital directly without taking any treatment. It is the former group of 62 patients who had maximum delay obviously because of taking some treatment before reaching this hospital. Out of 68 patients showing positive Widal test, only 47 (69.11\%) showed specific histological features of typhoid in the freshened margin of the ulcer. Remaining $21(30.88 \%)$ showed non-specific inflammation. Majority of the operated patients of enteric perforation had single perforation (70 patients i.e. 79.54\%), 16 patients (18.18\%) had two perforations and only 2 cases $(2.27 \%)$ had multiple perforations requiring resection and anastomosis. Eighty six patients were managed by simple closure of perforation in 2 layers (Inner by Polyglactin 910 continuous suture of 000 size while outer layer of interrupted silk suture of 000 size). Burst abdomen was found in 5.68\%, superficial dehiscence in $16.62 \%$, stitch abscess in $19.31 \%$, UTI in $3.40 \%$ as part of hospital acquired infection and residual intra-abdominal abscess was seen in $7.95 \%$ patients. In the present series, none had faecal fistula and there was no mortality. The duration of hospital stay ranged from 9 to 28 days with a mean of 14.8 days. Since mortality in the present series was nil due to initial screening at the hospitalisation stage, we have analysed the morbidity as prognostic factor of better and eventless outcome and given in table 5.

\section{CONCLUSION}

To conclude, the present series has shown that morbidity in delayed presentation and surgery, copious peritoneal contaminated fluid (More than 1 litre) and multiple perforations are the factors that lead to morbidity and prolonged hospitalisation.

\section{KEYWORDS}

Prognostic Factors, Enteric Perforation.

HOW TO CITE THIS ARTICLE: Goel KS, Goel N. Prognostic factors of morbidity in enteric perforation in a peripheral hospital. J. Evolution Med. Dent. Sci. 2016;5(90):6722-6725, DOI: 10.14260/jemds/2016/1519

Financial or Other, Competing Interest: None.

Submission 21-10-2016, Peer Review 02-11-2016,

Acceptance 05-11-2016, Published 10-11-2016.

Corresponding Author:

Dr. Kanwar Singh Goel,

Ex. Flight Lieutenant, Indian Air Force,

Maharaja Agrasen Hospital,

\#25/6, Opp. Bal Bhawan, Gandhi Nagar,

Scheme No. 6, Jind, Haryana.

E-mail: dr.kanwarsinghgoel@rediffmail.com

DOI: $10.14260 /$ jemds/2016/1519

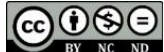

\section{BACKGROUND}

Intestinal perforation because of typhoid is quite common in the developing countries like India. Enteric perforation leads to generalised peritonitis and septicaemia. It is usually associated with high mortality and morbidity which further gets compounded at places where availability of medical facilities in India is poor. Clinical presentation may vary depending upon the time lapse between perforation and seeking an organised institutional care.

Although there is tremendous improvement in diagnostics, antibiotics, operative technology and monitoring, yet 
morbidity and mortality of typhoid perforation remains high. In a peripheral centre like ours, all patients are not taken up for further management. Patients who have normal chest and cardiac status with normal or near normal haematobiochemistry are taken so as to avoid unnecessary mortality and bad effects thereafter. Any patient where clinical evaluation suggests evidence of ARDS or septic shock are generally referred to a higher centre for better care and monitoring. We are presenting a series of 106 cases of typhoid perforation over last decade where disease profile, operative profile and outcome is analysed and based on this "proper select" approach, prognostic factors at a peripheral centre are worked out.

\section{MATERIALS \& METHODS}

A total of 106 cases were studied where after applying screening/filter of cardiac status, chest status, various clinical factors, haematological and biochemical factors, 88 cases were segregated for further management at our centre which is not as equipped as a tertiary care centre but has all necessary gadgets to deal with routine emergency. These 88 cases were proved to be of typhoid by Widal test and/or blood culture and/or histopathology of the excised margins of the ulcer during exploratory laparotomy.

Soon after decision of admitting the patient for further management, a detailed history was taken with particular emphasis on duration of fever, abdominal pain and constipation. Detailed physical examination was carried out laying emphasis on chest and cardiac status. The urine output was recorded and patient was routinely catheterised for monitoring urine output. Simultaneous fluid resuscitation and antibiotics, etc. was started and an abdominal radiograph in erect posture was taken to see the gas under diaphragm.

After optimisation, these patients were taken up for exploratory laparotomy by midline incision. Operative findings consisting of volume and quality of peritoneal fluid (intestinal, faeculent or pus or mixed) as well as site and number of intestinal perforations were recorded. All the peritoneal fluid was drained, perforation was repaired or resection carried out in two layers followed by thorough peritoneal lavage. A wide bore drain was placed in the pelvis and laparotomy wound was closed. Patient was closely monitored in post-operative period for vitals, urine output and general progress. Patient was allowed p.o. after positive bowel sounds or passing flatus. Any complication like superficial wound dehiscence or burst abdomen or stitch sepsis was accordingly managed. Stitches were removed on 12-14th post-operative day.

\section{RESULTS}

Mean duration of symptoms from onset to presentation in the hospital was $12.2 \pm 5.1$ days with range of 3 to 18 days. 56 patients presented within 2 weeks while 32 presented after 2 weeks from the onset of symptoms. Morbidity was 9 from former group and 20 in later group (Table 5).

In the present series, a total of 88 patients were taken in after applying the screening criteria on a total of 106 patients. Of these, 60 were males and 28 were females, the male to female ratio being 2.14:1. The mean age of the patients was $38.34( \pm 12.08)$, youngest being 18 years of age while oldest being 52 years of age. The various clinical features with which they presented are given in Table 1 where abdominal pain was almost a universal complaint.
As far investigations are concerned, all 88 patients showed gas under diaphragm. Ultrasonography was done in all the patients and showed free fluid ranging from ++ to +++ with dilated loops virtually in all the patients. Widal test was positive in only 68 patients $(77.27 \%)$ and blood culture was positive in 16 patients only.

Operation was done within 12 hours of onset of symptoms in 48 patients while 40 cases underwent surgery 12 hours of onset of symptoms. Morbidity was $9 / 48$ (18.75\%) in former group and 20/40 (50\%) in later group.

Average delay from onset of symptoms to operation was 18 hours which included time taken for optimisation for surgery after hospitalisation by way of administration of intravenous fluids also. Average time taken for optimisation was 3.8 hours. Detailed analysis revealed that delay was mostly before reaching the hospital. It was also found that 62 patients out of 88 had received some kind of treatment before reaching our hospital, in the form of intravenous fluids, antibiotics and analgesics. Remaining 26 patients reached the hospital directly without taking any treatment. It is the former group of 62 patients who had maximum delay obviously because of taking of some treatment before reaching this hospital.

Out of 68 patients showing positive Widal test, only 47 (69.11\%) showed specific histological features of typhoid in the freshened margin of the ulcer. Remaining 21 (30.88\%) showed non-specific inflammation; but since they all had positive Widal test, they were eventually considered cases of enteric perforation.

Majority of the operated patients of enteric perforation had single perforation (70 patients i.e. $79.54 \%$ ), 16 patients $(18.18 \%)$ had two perforations and only 2 cases $(2.27 \%)$ had multiple perforations requiring resection and anastomosis. Eighty-six patients were managed by simple closure of perforation in 2 layers (Inner by Polyglactin 910 continuous suture of 000 size while outer layer with interrupted silk suture of 000 size).

The complications encountered are listed in table no 4. Burst abdomen was found in $5.68 \%$, superficial dehiscence in $16.62 \%$, stitch abscess in $19.31 \%$, UTI in $3.40 \%$ as part of hospital acquired infection and residual intra-abdominal abscess was seen in $7.95 \%$ patients. In the present series, none had faecal fistula and there was no mortality. The duration of hospital stay ranged from 9 to 28 days with a mean of 14.8 days.

Since mortality in the present series was nil due to initial screening at the hospitalisation stage, we have analysed the morbidity as prognostic factors of better and eventless outcome and are given in table 5.

\section{DISCUSSION}

Ileal perforation following typhoid fever is still one of the commonest cause of peritonitis in developing and underdeveloped world. It is reported to be rare phenomena in the western world. Males have been found to be dominantly affected in the present series. Males are said to be more exposed to the infection with an increased risk of necrosis and perforation due to immune mechanism and genetic predisposition.(1) Typhoid disease is a disease of young productive age group. Although the age group profile of the present series compares well with some of the published 
series, $(2,3,4)$ yet the mean age of the present series is slightly

The presenting symptoms and clinical features are by and large quite similar to any other acute abdominal condition. The decision of laparotomy was largely taken by the fact of presence of gas under diaphragm in patient having features of generalised peritonitis on clinical evaluation (100\%). The diagnosis of enteric perforation is of course suspected by history of fever and positive Widal test (77.27\%). After reviewing the histological profile of freshened edges of the ulcer, it was found that even those who had positive Widal test, histologically there was no specific findings suggestive of typhoid and showed only non-specific inflammation (30.88\% of those showing positive Widal test).

The delay in operation, wherever occurred was mainly due to pre-hospital constraint viz taking some form of treatment outside or transport or non-availability of transport or sometimes non-availability of the decision making attendants like parents.

Typhoid fever is caused by salmonella typhi in areas where poor socioeconomic strata and unhygienic conditions prevail. The incubation period is 1-14 days and clinical features start with bacteraemia, high grade fever and signs of systemic sepsis. Blood counts are generally low which was seen in majority of our patients i.e. 86/88 (97.72\%). Bradycardia was found in $17.85 \%$ patients. Later bacteria localises in Peyer's patches where capillary thrombosis leads to necrosis and perforation takes place usually in $3^{\text {rd }}$ week of the disease. The terminal part of intestine (Approximately $60 \mathrm{~cm}$ ) is particularly oedematous and friable. Late presentation, delay in operation, multiple perforations and presence of copious peritoneal fluid (laden with pus and faeculent material to the tune of more than one litre) adversely affects the outcome i.e. mortality or morbidity. The quality of peritoneal fluid and delay in operation also determines the friability of gut. The literature also mentions that profuse peritoneal exudates do affect the outcome. $(3,6)$

Surgery offers best chance of survival in enteric perforation.(7) Although a variety of procedures are undertaken for enteric perforation viz closure, resection and anastomosis and ileostomy. In the present series, majority of cases settled with simple closure of perforation and resection and anastomosis was needed in only 2 patients. Faecal fistula is a catastrophic complication but luckily was not seen in the present series due to initial screening of cases at the hospitalisation stage. Burst abdomen did of course occur in $5.68 \%$ patients.

Mortality of the present series is nil largely because of the fact the cases were screened at the initial stage and serious cases requiring care at tertiary care centre were referred at the outset. Nonetheless, the mortality is reported in the range of 9 to $43 \%{ }^{(3)}$ in the literature. However, the reports of mortality are $6.8 \%$ from Nepal(2) and $10.5 \%$ from India.(4) Mortality rates reported from the western world is $1.5-2 \%$ where socioeconomic infrastructure is well developed.(8)

Incidence of faecal fistula is zero in present series, but it is reported to be $3.8 \%$, , $\left.^{9}\right) 7.8 \%$, ,(2) $8 \%(3)^{(3)}$ and $16.5 \%$.(4) Burst abdomen added to the morbidity in the present series.

To conclude, the present series has shown that morbidity in enteric perforation is affected by sex, delayed presentation higher than other series.(5)

and surgery, copious peritoneal contaminated fluid (More than 1 litre) and multiple perforations are the factors that lead to morbidity and prolonged hospitalisation.

\begin{tabular}{|c|c|c|}
\hline Symptoms & Male & Female \\
\hline Pain Abdomen & $60(100 \%)$ & $28(100 \%)$ \\
\hline Fever & $60(100 \%)$ & $28(100 \%)$ \\
\hline Vomiting & $51(85 \%)$ & $28(100 \%)$ \\
\hline Constipation & $60(100 \%)$ & $28(100 \%)$ \\
\hline Bradycardia & $22(36.66 \%)$ & $05(17.85 \%)$ \\
\hline \multicolumn{2}{|c|}{ Table 1. (Showing Prevalence of Various } \\
Symptoms in Present Series $\mathbf{N = 8 8 )}$ \\
\hline
\end{tabular}

\begin{tabular}{|c|c|}
\hline No. of Perforations & No. of Cases \\
\hline Single Perforation & $70(79.54 \%)$ \\
\hline Two Perforations & $16(18.18 \%)$ \\
\hline Multiple Perforations & $2(2.27 \%)$ \\
\hline Table 2. (Showing No. of Perforations $\mathbf{n = 8 8 )}$ \\
\hline
\end{tabular}

\begin{tabular}{|c|c|}
\hline $\begin{array}{c}\text { Test Showing Positive } \\
\text { Evidence of Typhoid }\end{array}$ & No. of Cases \\
\hline Positive Widal Test & $68 / 88(77.27 \%)$ \\
\hline Positive Histological Evidence & $47 / 68(69.11 \%)$ \\
\hline $\begin{array}{c}\text { Non-Specific Inflammation } \\
\text { on Histology }\end{array}$ & $21 / 68(30.88 \%)$ \\
\hline \multicolumn{2}{|c|}{ Table 3. (Showing Various Tests) } \\
\hline
\end{tabular}

\begin{tabular}{|c|c|}
\hline Complications & Number of Patients \\
\hline Burst abdomen & $5(5.68 \%)$ \\
\hline Superficial dehiscence & $12(16.63 \%)$ \\
\hline Stitch sepsis & $17(19.31 \%)$ \\
\hline Urinary tract infection & $3(3.40 \%)$ \\
\hline Faecal fistula & 0 \\
\hline Intra-abdominal abscess (PUO) & $7(7.95 \%)$ \\
\hline Table 4. (Showing Various Complications $\mathbf{n = 8 8 )}$ \\
\hline
\end{tabular}

\begin{tabular}{|c|c|c|}
\hline Parameters & Factors & $\begin{array}{c}\text { Number of Cases/ } \\
\text { Percentage having } \\
\text { Morbidity }\end{array}$ \\
\hline \multirow{2}{*}{ Sex } & Male & $17 / 60(28.33 \%)$ \\
\hline & Female & 9/28 (32.14\%) \\
\hline \multirow{2}{*}{$\begin{array}{l}\text { Duration of } \\
\text { Symptoms }\end{array}$} & $\begin{array}{c}\text { Within Two } \\
\text { Weeks }\end{array}$ & $9 / 56(16.07 \%)$ \\
\hline & $\begin{array}{c}\text { More than } \\
\text { Two Weeks }\end{array}$ & $20 / 32(62.5 \%)$ \\
\hline \multirow{2}{*}{$\begin{array}{l}\text { Delay in } \\
\text { Operation }\end{array}$} & $\begin{array}{l}\text { Less than } \\
12 \text { Hours }\end{array}$ & $9 / 48(18.75 \%)$ \\
\hline & $\begin{array}{l}\text { More than } \\
12 \text { Hours }\end{array}$ & $20 / 40(50 \%)$ \\
\hline \multirow{3}{*}{$\begin{array}{c}\text { No. of } \\
\text { Perforations }\end{array}$} & $\begin{array}{c}\text { Single } \\
\text { Perforation }\end{array}$ & $2 / 70(2.85 \%)$ \\
\hline & $\begin{array}{c}\text { Two } \\
\text { Perforations }\end{array}$ & $6 / 16(37.5 \%)$ \\
\hline & $\begin{array}{c}\text { Multiple } \\
\text { Perforations }\end{array}$ & $01 / 2(50 \%)$ \\
\hline \multirow{2}{*}{$\begin{array}{l}\text { Amount of } \\
\text { Peritoneal } \\
\quad \text { Fluid }\end{array}$} & $\begin{array}{l}\text { Less than } \\
\text { one litre }\end{array}$ & 17/88 (19.31\%) \\
\hline & $\begin{array}{l}\text { More than } \\
\text { one litre }\end{array}$ & $22 / 88(25 \%)$ \\
\hline $\begin{array}{c}\text { Burst } \\
\text { Abdomen }\end{array}$ & & $5 / 88(5.68 \%)$ \\
\hline
\end{tabular}




\begin{tabular}{|c|c|c|}
\hline \multirow{2}{*}{$\begin{array}{l}\text { Type of } \\
\text { Operation }\end{array}$} & Simple Closure & $18 / 86(20.93 \%)$ \\
\hline & $\begin{array}{c}\text { Resection and } \\
\text { Anastomosis }\end{array}$ & $01 / 2(50 \%)$ \\
\hline
\end{tabular}

\section{REFERENCES}

1. Santillana M. Surgical complications of typhoid fever: enteric perforation. World J Surg 1991;15(2):170-5.

2. Karmacharya B, Sharma VK. Results of typhoid perforation management: our experience in Bir hospital, Nepal. Kathmandu University Medical J 2006;4(1):22-4.

3. Adesunkanmi AR, Ajao OG. Prognostic factors in typhoid ileal perforation: a prospective study in 50 patients. J R Coll Surg Edin 1997;42(6):395-9.

4. Beniwal US, Jindal D, Sharma J, et al. Comparative study of operative procedures in typhoid perforation. Ind J Surg 2003;65(2):172-7.
5. Ameh EA, Dogo PM, Attah MM, et al. Comparison of three operations for typhoid perforation. $\mathrm{Br} \quad \mathrm{J}$ Surg 1997;84(4):558-9.

6. Atoyebi OA, Adesanya AA, Atimomo CE, et al. Prognostic factors of typhoid perforation in Lagos. Nig Qt J Hosp Med 1999;9(1):78-83.

7. Olurin E0, Ajayi 00, Bohrer SP. Typhoid perforations. J R Coll Surg 1972;17(6):353-63.

8. Carmeli Y, Raz R, Schapiro JM, et al. Typhoid fever in Ethiopian immigrants to Israel and native- born Israelis: a comparative study. Clin Inf Dis 1993;16(2):213-5.

9. Edino ST, Yakubu AA, Mohammed AZ, et al. Prognostic factors in typhoid ileal perforation: a prospective study of 53 cases. J Natl Med Assoc 2007;99(9):1042-5. 